\title{
INFORMATION AS THE FACTOR OF ACCELERATION IN THE CONDITIONS OF GLOBAL DEVELOPMENT
}

\author{
Abdumalikov Abdulatif Abidzhanovich, \\ The teacher, Fergana State University. \\ Republic Uzbekistan
}

doi http://dx.doi.org/10.26739/2573-5616-2018-3-2-4

\begin{abstract}
: the author investigated questions of interrelation of globalisation and a role of information of a society. In article the essence of global problems at the present stage of development of the country, an essence of their self-expression and display in the conditions of a civil society is considered. Attempt to open feature of a problem of information process on which decision the destiny of all people and each person depends is made.

Key words: global problems, ecology, mankind, the present, a civil society, social progress, region, the information, resources.
\end{abstract}

\section{INTRODUCTION}

Studying of problems of information of a society in the conditions of global development to become actual. The important role in understanding of global problems is played by their scale characteristics. The term testifies to it "global", different strongly pronounced ecological окрашенностью. However the given term at all did not describe social development in childhood of the world or even three centuries ago. To it there were reasons: the progress of mankind accompanied by expansion of borders and scales of interaction with the nature, only in the conditions of a civil society has found really global parametres, has found out the features and the contradictions nowadays shown in the form of global problems. Mentioning the world as a whole, they represent the certain form of development of global character of contradictions of human activity, including expansions of its spatial borders. Expressing various contradictions of a single whole, namely social progress, progress of all mankind, global problems thereby are connected among themselves. It is impossible to consider that progress is one, and global problems - something other, interfering its development.

\section{METODOLOGY}

Global problems at the present stage of development of mankind an essence its self-expression and display in planetary scales. These are the 
sharpest contradictions on which decision the destiny of all people and each person depends. It is quite clear that global problems act as a subsystem of that system of development which represents mankind progress, inconsistent social development on a global scale. Through system "mankind" in unity of its interrelations and development laws global problems, displaying contradictions of social progress, incorporate to the last. The first President of Republic Uzbekistan I.A.Karimov noticed that "the evolutionary us evolutionary and stage-by-stage way of development of Uzbekistan, based on five known principles and recognised in the world as" the Uzbek model "reforms became the major factor of all our achievements, certainly, and today life proves, this way is how much correct. That in it the natural, historical, national, demographic and ecological features inherent in Uzbekistan are comprehensively considered testifies to advantages and efficiency of our model of development, and it has completely justified herself in practice ". [4]

In addition to social communications system character of global problems amplifies the system organisation of the nature surrounding mankind as the ecosystem getting nowadays global character. Interaction of people and them generality, among themselves, and also the person and mankind with the nature also is that base of communications and that integrity which cause system character of global problems. About global problems it is possible to speak as about independent system, having, of course, in a kind that it acts only as a subsystem of system "mankind". Occurrence of global problems, formation of their system as single whole in which parties, or parts, influence and against each other and on whole, confirms necessity of consideration of development of a civil society and the nature not separately that quite often became, and in common, as co-operative, that is socially natural, development. Occurrence and aggravation of global problems - the certificate of this mutual conditionality accepted largescale forms and having unprecedented displays. At the same time it and the certificate of that abstraction of natural type of development from social any more does not answer a reality of a civil society. Now progress of mankind does not represent independent development of the separate countries independent from each other and the people.

Global problems of mankind possess a number of characteristic features: first, they infringe on interests of all mankind and each person, secondly, they have got the international character, thirdly, they demand for the decision of the international cooperation on a global scale, concentration of efforts of all countries and nations of the world, at last, fourthly, they form global system in which frameworks the decision of one problem is closely interconnected with the decision of others. At the same time that the global phenomenon became a problem, one more important condition 
is necessary. Namely there should be a basic contradiction in development of this or that problem, menacing by crisis to development as societies as a whole, and the separate person. It, for example, ecological crisis, threat of thermonuclear accident, regional military conflicts. Such contradiction in development of socially-information processes exists and carries the name "information crisis"." Information crisis "us is considered as inconsistent unity" information explosion "and" information hunger ", that is as original" information hunger "in the conditions of information explosion.

First, there is a contradiction between the limited possibilities of the person to perceive and overwork the information and existing powerful streams again arriving and files of the stored information.

Secondly, information crisis consists also in manufacture of a significant amount of surplus information which constrains or essentially complicates consumption of the useful, valuable information.

Thirdly, infringement of integrity of the scientific and social communications, consisting in preference of elite and group interests universal and so on creates the certain economic, political, social and other barriers which are not allowing the information to carry out the integrating role in development of a society. On the one hand, the information factor has made in life of a human civilisation one of the radical changes for all its history - has connected the world in uniform information system. But, on the other hand, - the given unity carries formal, superficial, basically technical character.

\section{RESULTS}

In the conditions of a civil society the information represents a global problem, but at all is not the main and actually unique factor of aspiration of mankind to global unity as it is drawn by authors of "an information society". Moreover, it finds global characteristics thanks to the specificity not individually, and in intrinsic unity with other universal attributes of human existence and development, being integrally intertwined in social and economic and other processes, promoting acceleration of their development and formation of the global status. Formation of global character of a problem of the information is connected and with that unbiased fact that the information and first of all the scientific information is integral from other global problems. The possibility of reckoning of a problem of the information established above to global problems of modern social development testifies in favour of that the information represents itself as the factor of global development. However detection of the general, inherent in a problem of the information and other global problems, yet does not speak about specificity of the considered phenomenon. It is necessary 
to reveal it, focusing attention on features of a problem of the information, having is universal-global value.

The increase in a share of an information work in a social production testifies that the information turns to a subject of human work more and more. Thus, a tendency of the increasing filling of social activity by the information maintenance - shift from activity with is material-material subjects to activity with the information which considerable part in a society has spiritual, ideal character. Moreover, growth of information making social activity has affected and a number of global properties of regions. The given global phenomenon also has "the information" nature for reflects that fact that the mankind prefers to transfer data by means of radio-waves.

The following feature of development of the socially-information processes, connected with finding of global characteristics by them, consists that the information starts to play a role of the major resource which in certain degree or saves, or even replaces some other resources. When it is a question of the information as about the factor of global development means that a subject of human activity and means of its use. As the subject of a special information work, the information is appreciated the maintenance, that is for ideal parametres. In this plan it represents the ideal resource saving material resources. At the same time information means, that is the information technics and technology, in our opinion, enter into this resource (information) also (computers, communication facilities etc.) Without which or It is impossible, or it is inefficient to process, transfer the information and etc. Basic changes in development computertechnicians are not in the last instance caused it scientific, and a resource economical. In it its difference fromto save resources manufactures, in particular, from overwhelming number of traditional branches of the mechanical engineering dealing with substance and energy. These last as though give inertia to development of branches of economy which in comparison with the computer science industry develops evolution. Thus, the information factor of global development has two aspects - ideal and material, acting as a subject and as means of information of a civil society.,

\section{DISCUSSION}

It is known that resources share on renewed (reproduced) and not renewed, and the first get the increasing value for the further progress of the country as all social activity in the conditions of limitation of nonreproducible resources is guided by use of that orIt is boundless, or the unlimited number of times can be reproduced. The information, first of all scientific and technical, perhaps, under the status is closer to renewed resources. To carry it completely to renewed resources it is impossible, as property of a reuse not all information owing to the ageing and of some 
other qualities, say, noncompetitiveness possesses. As to the scientific and technical information displaying fundamental laws of the nature and a society, that, no doubt, the such information, documentary the fundamental knowledge in the form convenient for its further movement on social communications, concerns renewed resources. The fundamental scientific and technical information can be used infinite quantity of times. Hence, under the status it can be equal to renewed material resources, though under the maintenance it not material, but an ideal phenomenon.

Unlike the opinion quite often meeting in the scientific literature concerning global development, the intensification problem should be considered as one of historically first global problems. Usually as that name an environmental problem as genetically the earliest in developing system of global problems.

Same value of the information is caused also. Without adequate information support the decision of any of problems of universal value is impossible. The information promoted that for rather short historical time interval global problems have appeared in sight of world community and became originally universal not only inherently, but also by a recognition which they have won. Anything so does not promote growth of understanding of a generality of destinies of mankind as consciousness of a global problematics, and it is immanently inseparable from processes of global international communications.

\section{CONCLUSIONS}

In the conditions of modernisation of a society the information becomes the important factor of the decision of social and economic problems only through an intensification, that is through the social and economic process of the accelerated advance opening new horizons to development of productive forces and relations of production, translating human progress on an intensive way. Occurrence of the majority of global problems coincides on time with transition of the countries to a way of mainly intensive development. It also confirms communication of processes of an intensification and globalisation. And though, in our opinion, not all global problems are caused by transition to intensive development, but formation of global character of problems already unequivocally connects them with Intensificationprocesses. Globalisation testifies not to necessity of turning of this or that kind of the social activity which accepted the international scales and has faced natural restrictions, and about necessity of its transition to an intensive way of development.

Thus, not only to establish the fact of formation of the information the global factor of development, but also it is necessary to investigate the internal mechanisms responsible for finding by a problem of the information of the global status. 
In the first: the information plays a main role in transfer of all spheres of social activity into the intensive way of development which are the unique form and a mainstream of the further acceleration of social and economic progress.

In the second: the problem of a survival of a civilisation and acceleration of its progress acts as an ultimate goal of more and more wide and allround use of the information playing an important role as in internal social and economic processes of the country.

\section{Reference}

1. Antons And. To. An information society. Bases of information culture: Studies. The grant at the rate "Introduction in computer science" / Mosk.staet. Un.services. - M: Моск.staet. Un. services, Mytischi: Publishing house Mosk. staet. Un y woods, 2000

2. Abdurazakov M. M, Gadzhiev G.M.Sistemno-integrativnye components in information culture of the future teacher in the field of computer science and information technology//Standards and monitoring in formation. - M, 2004. - N 1. - With. 50-52 Code number: 08807634

3. Vasilenko, L.A.. And. Information culture in government system / Dews. акад. гос. Services at the President Pos. Federations. - M: Publishing house RAGS, 2004. - 147 with., columns the Code number: 103430411 (the Russian Academy of Sciences)

4. Karimov I.A.Performance Islam Karimov at solemn ceremony of the introduction into a post of the President of Republic Uzbekistan at joint session of chambers Oly Mazhlisa.//the National word, on April, 11th 2015

5. Cultural science the XX-th century. - M, 2000. - N 2. - With. 233-254 Ref. The code number: 23287632

6. Scvorcov L.V.. Russia: a problem of spirituality and information culture//Abdurazakov M. M, Gadzhiev G.M.Sistemno-integrativnye components in information culture of the future teacher in the field of computer science and information technology//Standards and monitoring in formation. - M, 2004. - N 1. - With. 50-52 Code number: 08807634

7. http://fio.samara.ru/works/15/ecology/part5.htm - the Library lesson "the Global problem of the present - threat of ecological crisis

8. The informer Moscow university. Scientific magazine. Volume 12. Political subject N6. M.:2010. P:1

9. Modesov S.A. "Spending of information as the factor geopolitical competition ". M.: 1997. P:16-17.

10. Okinovskaya N.A. " The international charter of society information ". N 8. M.:2000. P: 51-56. 